\title{
The effect of autoimmune retinopathy on retinal vessel oxygen saturation
}

\author{
Maria Waizel $^{1}$ - Cengiz Türksever ${ }^{2} \cdot$ Margarita G. Todorova $^{3,4}$ \\ Received: 16 November 2017 / Accepted: 28 February 2018 / Published online: 22 May 2018 \\ (c) The Royal College of Ophthalmologists 2018
}

\begin{abstract}
Purpose To study the retinal vessel oxygen saturation alterations in patients with autoimmune retinopathy (AIR) and patients with autoimmune retinopathy associated with retinitis pigmentosa (AIR-RP) in comparison with healthy controls and patients with isolated retinitis pigmentosa (RP).

Design Prospective, cross-sectional, and non-interventional study.

Subjects Retinal vessel oximetry (RO) was performed on a total of 139 eyes: six eyes suffering from AIR and four eyes with AIR-RP were compared to 59 healthy control eyes and to 70 eyes with RP.

Methods A computer-based program of the retinal vessel analyser unit (IMEDOS Systems UG, Jena, Germany) was used to evaluate retinal vessel oxygen saturation. The mean oxygen saturation in the first and second branch retinal arterioles (A$\left.\mathrm{SO}_{2}\right)$ and venules $\left(\mathrm{V}-\mathrm{SO}_{2}\right)$ were measured and their difference $\left(\mathrm{A}-\mathrm{V} \mathrm{SO} \mathrm{SO}_{2}\right)$ was calculated. In addition, we measured the diameter of the retinal arterioles (D-A) and venules (D-V).

Main outcome measures Oxygen metabolism is altered in patients with isolated AIR and AIR-RP.

Results Both, AIR and AIR-RP groups, differed from healthy controls showing significantly higher $\mathrm{V}-\mathrm{SO}_{2}$ values and significantly lower A-V SO 2 values $(p<0.025)$. In addition, the AIR-RP group could be differentiated from eyes suffering from isolated RP by means of significantly higher $\mathrm{V}-\mathrm{SO}_{2}$ values. Comparing retinal vessel diameters, both, the AIR and AIR-RP groups, presented with significant arterial $(p=0.05)$ and venular $(p<0.03)$ vessel attenuation than the healthy control group. Conclusions Based on our results, in analogy to patients suffering from RP, oxygen metabolism seems to be altered in AIR patients.
\end{abstract}

\section{Introduction}

Retinal vessel oximetry (RO) is a noninvasive method to determine the oxygen saturation of retinal arterioles and venules [1-4]. In the retina, oxygen is a crucial metabolite

Electronic supplementary material The online version of this article (https://doi.org/10.1038/s41433-018-0122-3) contains supplementary material, which is available to authorized users.

Margarita G. Todorova

margarita.todorova@unibas.ch

1 Department of Ophthalmology, University of Basel, Basel, Switzerland

2 Department of Ophthalmology, VISTA Clinik, Basel, Switzerland

3 Department of Ophthalmology, University of Basel, Basel, Switzerland

4 Department of Ophthalmology, Cantonal Hospital St. Galllen, St. Galllen, Switzerland for maintaining proper visual function [5, 6]. RO enables now to evaluate in vivo metabolic alterations of the retina $[7,8]$.

In eyes suffering from retinitis pigmentosa (RP), recent studies have demonstrated a severe increase in retinal vessel saturation, when compared to healthy controls [9-15]. While these studies suggested RO to be a reliable and objective metabolic outcome measurement, it is proposed as a useful tool to support the monitoring of disease progression and to evaluate the success of future treatments in RP.

Autoimmune retinopathy (AIR) leads to a rapidly occurring photoreceptor dysfunction [16, 17]. Although, the molecular mechanisms are not yet clearly understood, AIR is supposed to be triggered by a cross-reaction between antigens expressed by the underlying tumor and retinal proteins [17-20]. Careful assessing for clinical features similar to RP, as: subacute progressive visual deterioration, nyctalopia, scotomas and visual field defects, and clinical signs, as: retinal vascular attenuation, retinal pigment epithelium mottling or atrophic degenerative changes, waxy 
optic disc pallor or abnormalities in the electroretinogram, can help make the diagnosis of AIR [17, 21-27].

To the best of our knowledge, there has been no previous investigation of the retinal oximetry values in patients with AIR. Even if RP and AIR are different clinical entities, both are associated with autoimmune antiretinal antibodies, which most likely play a pathologic role in the progression of outer retinal degeneration [28]. Therefore, in analogy to RP [9-15], altered metabolic function is also expected to occur in patients with AIR. Furthermore, even if a rare case in daily clinical practice, already preexisting RP can be aggravated by AIR (AIR-RP) [28, 29]. Therefore, it is worth to further evaluate whether the metabolic function in patients with AIR and in patients with autoimmune retinopathy associated with retinitis pigmentosa (AIR-RP) share any different features.

Thus, the primary goal of this study is to evaluate retinal vessel oxygen saturation in patients with autoimmune retinopathy and patients with AIR-RP. The secondary goal of the study is to compare the metabolic findings of AIR and AIR-RP patients to those of healthy controls, as well as to patients with isolated RP, as a simple model for progressive outer receptor degeneration.

\section{Methods}

Prospective observational study of 5 patients suffering either from AIR (patients no. 1-3) or combined AIR and RP (AIR-RP; patients no. 4-5), 46 patients with isolated RP and 36 healthy controls were performed: all participants were examined from January 2015 until December 2016 in a single centre for ophthalmology (University of Basel, Department of Ophthalmology, Switzerland). This study was approved by the local authorities (Ethics Commission of Central and Northern Switzerland, EKNZ, Basel, Switzerland) with a positive vote for prospective observational investigations (trial number EKNZ BASEC 2016-01054).

\section{Subjects}

We recruited and investigated a total of six eyes of three patients diagnosed with isolated AIR, four eyes of two patients diagnosed with a combination of AIR and RP, 70 eyes of 46 patients with isolated RP and 59 eyes of 36 healthy controls. The clinical AIR and RP phenotype was built from the subjective signs, clinical, and electrophysiological findings are described in Table 1 and our supplemental document.

Apart from the diagnostic imaging and electrophysiology, we performed RO in our AIR and AIR-RP patients. The RO data of healthy controls and RP patients from our data bank were taken for comparison. Our RP patients' (30\% and 16 ${ }^{*}$ ) age ranged from 20 to 60 years $\left(40.7 \pm 11.0\right.$, mean \pm SD), and our controls' (22ᄋ and 16 $\left.{ }^{\star}\right)$ age ranged from 29 to 74 years $(45.9 \pm 14.1$, mean \pm SD) .

We determined the inclusion criteria for all AIR, AIR-RP patients, controls, and RP patients to be as follows: Caucasian origin, stable fixation, and refractive error of $<6$ diopters. Patients and controls who had previous ocular surgery or ocular and systemic pathology (as for instance, diabetes mellitus, or neurological disease) that may influence the RO data were not included in this study. Additional exclusion criteria were fundus oximetry imaging with inadequate quality, or an expressed unwillingness to participate in the study. The research procedures were carried out in accordance with institutional guidelines and the Declaration of Helsinki. Informed consent was obtained from all participants before the commencement of the examination.

All participants underwent detailed ophthalmic examination, which included among others refraction, bestcorrected visual acuity (Snellen charts), intraocular pressure examination by applanation, slit lamp examination, biomicroscopy, and fundoscopy.

Prior to RO measurements, both pupils were maximally dilated (Tropiphen $10 \mathrm{ml}$ eye drops prepared in our institutional pharmacy as a combination of Tropicamide $0.5 \%$ and phenylephrine $1 \%$ ).

\section{RO acquisition and analysis}

We used a spectrophotometric oximetry unit for RO (IMEDOS Systems UG, Jena, Germany; Fundus camera FF450, Carl Zeiss Meditec AG, Jena, Germany). Fundus images were recorded using a camera system, DCC Digital Camera KY-F75 (JVC Inc., Yokohama, Japan) coupled to the Zeiss fundus camera. Based on the differential light imaging characteristics at $610 \mathrm{~nm}( \pm 10 \mathrm{~nm})$ and at $548 \mathrm{~nm}( \pm 10 \mathrm{~nm})$ wavelengths, the software operating the system (VISUALIS; IMEDOS Systems UG) differentiates simultaneously the oxygenated hemoglobin from the deoxygenated, measuring thus the oxygen saturation level in the examined retinal vessel. Four test-retest fundus images per eye were obtained $[10,11]$. We evaluated the mean oxygen saturation $(\%)$ in almost all first and second branch retinal arterioles $\left(\mathrm{A}-\mathrm{SO}_{2}\right)$ and venules $\left(\mathrm{V}-\mathrm{SO}_{2}\right)$ within $0.5-1.0$ optic disc diameters from the disc margin, and calculated their difference, the $\mathrm{A}-\mathrm{V}$ $\mathrm{SO}_{2}$ (Fig. 1). In addition, we measured the diameter $(\mu \mathrm{m})$ of the retinal arterioles (D-A) and venules (D-V).

Study endpoints were the mean arterial $\left(\mathrm{A}-\mathrm{SO}_{2}\right)$, venular $\left(\mathrm{V}-\mathrm{SO}_{2}\right)$ oxygen saturation, their difference $\left(\mathrm{A}-\mathrm{V} \mathrm{SO} \mathrm{S}_{2}\right)$, as well as the mean diameter of the retinal arterioles (D-A) and venules $(\mathrm{D}-\mathrm{V})$ determined by spectrophotometric oximetry. For statistical evaluation ANOVA-based linear mixedeffects model was performed (IBM SPSS Statistics ${ }^{\circledR}$, Version 22.0.0.0), which allows taking the dependency of the left and right eye in the same subject into account and is 


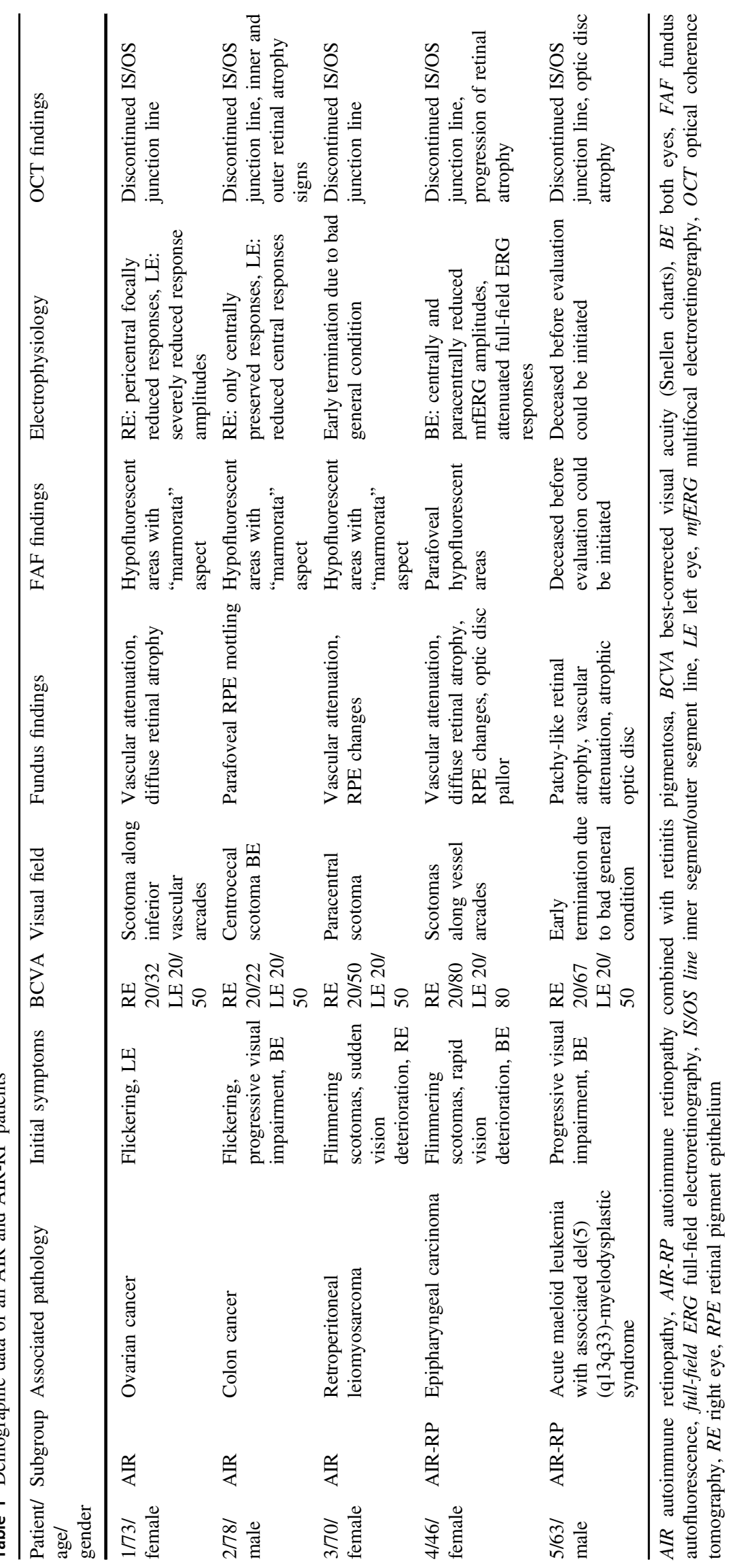


Fig. 1 Presents an example of a vessel map in a healthy control subject (a), in a patient with retinitis pigmentosa $(\mathbf{b})$, in a patient with autoimmune retinopathy $(\mathbf{c})$, and combined retinitis pigmentosa and autoimmune retinopathy $(\mathbf{d})$. Oxygen saturation was measured in almost all first or second branch retinal arterioles and venules within $0.5-1.0$ optic disc diameter distance from the optic disc margin
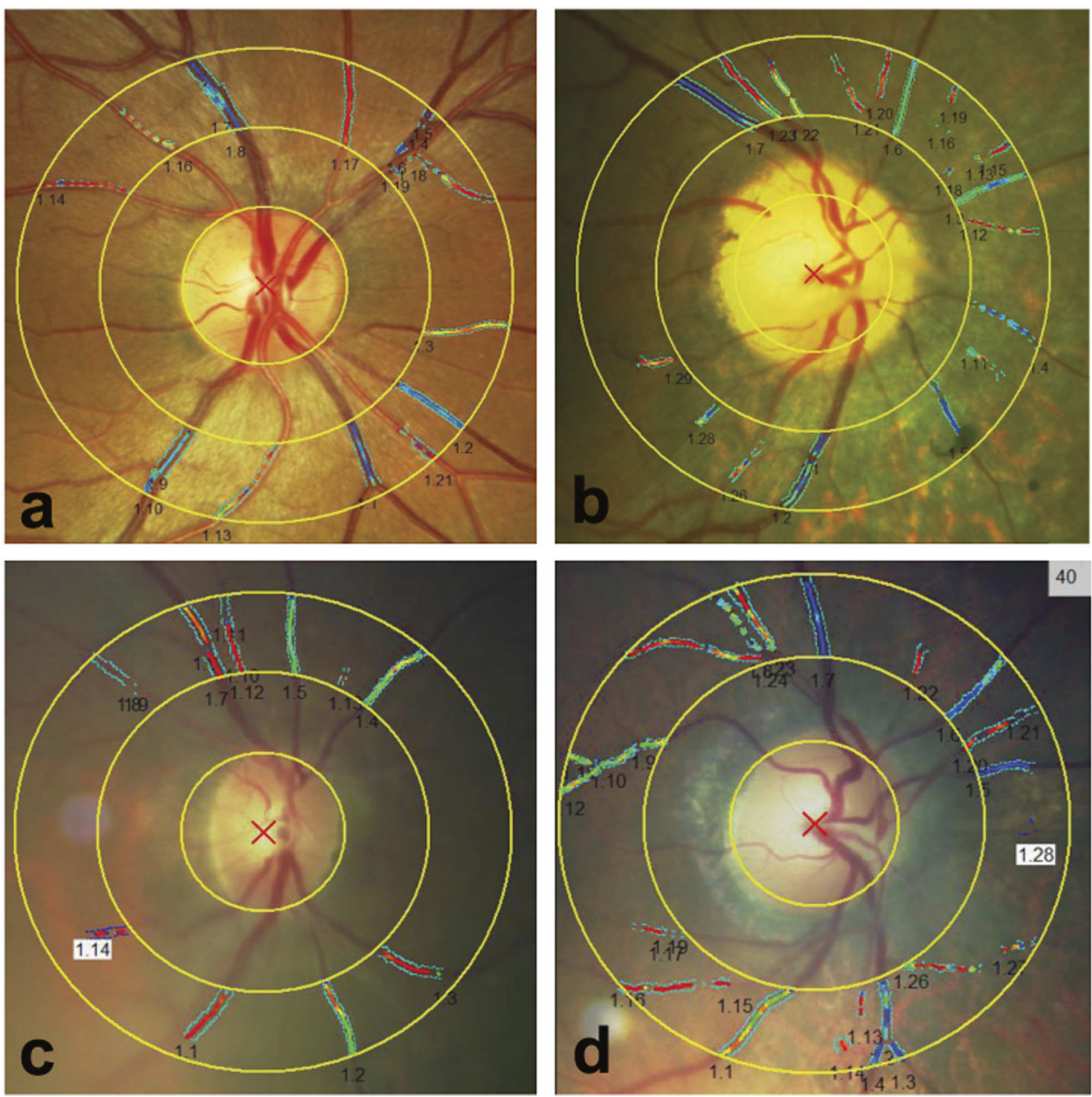

suitable for repeated measurements. To predict the effect of the underlying disease on oximetry measurements, the eyeand the group effect were taken into account, where the eye and the group were treated as a fixed factor and the subject as a random factor. Results are presented as adjusted means and standard deviation $( \pm \mathrm{SD})$ of all examined groups, with their corresponding mean differences and $p$-values. $P<0.05$ was defined as statistically significant.

\section{Results}

\section{Oximetry results}

\section{Comparison with healthy control eyes}

In general, AIR patients (isolated AIR and AIR-RP) differed from controls, when the oxygen saturation parameters were taken into account (the A-SO, $\mathrm{V}_{2} \mathrm{SO}_{2}$, and $\mathrm{A}-\mathrm{V} \mathrm{SO} \mathrm{S}_{2}$ ).

In controls, the mean $\pm \mathrm{SD} \mathrm{A}-\mathrm{SO}_{2}$ and $\mathrm{V}-\mathrm{SO}_{2}$ of the retina were measured at $93.91 \pm 4.09 \%$ and $56.23 \pm 6.45 \%$, respectively (Table 2). The mean $\pm \mathrm{SD} \mathrm{A}-\mathrm{V} \mathrm{SO} \mathrm{S}_{2}$ in controls was
$37.67 \pm 5.75 \%$. In patients with AIR and AIR-RP, the mean retinal $\mathrm{A}_{-} \mathrm{SO}_{2}$ increased to $98.07 \pm 1.90 \%(p=0.073)$ and significantly to $100.40 \pm 5.79 \%(p=0.021)$. Correspondingly, the mean $\pm \mathrm{SD} \mathrm{V}-\mathrm{SO}_{2}$ levels increased significantly to $67.79 \pm$ $6.87 \%(p<0.001)$ and $72.24 \pm 9.04 \%(p<0.001)$, whereas the A-V SO 2 decreased significantly to $30.29 \pm 7.38 \%(p=0.024)$ and to $28.16 \pm 10.98 \%(p=0.016)$.

Thus, an interesting finding in the present study is that the AIR and AIR-RP groups differed from the healthy controls, both showing significantly higher $\mathrm{V}-\mathrm{SO}_{2}$ values and significantly lower $\mathrm{A}-\mathrm{V} \mathrm{SO} \mathrm{S}_{2}$ values.

\section{Comparison with eyes suffering from RP}

Consistent with the results of previous studies [9-15], isolated RP differed from controls: the mean retinal A- $\mathrm{SO}_{2}$ and $\mathrm{V}-\mathrm{SO}_{2}$ levels increased to $97.94 \pm 6.41 \%(p<0.001)$ and $62.20 \pm 8.20 \%(p<0.001)$ and the $\mathrm{A}-\mathrm{V} \mathrm{SO}_{2}$ decreased to $35.73 \pm 8.61 \%(p=0.15)$ (Table 2).

The subgroup analysis revealed that the $\mathrm{SO}_{2}$ values of patients with AIR and AIR-RP also differed from eyes suffering from RP: more precisely, the AIR-RP group showed a 
Table 2 Statistical analyses of retinal vesel saturation and retinal vessel diameter values calculated in subgroups (controls, isolated AIR and AIR$\mathrm{RP})$.

\begin{tabular}{|c|c|c|c|c|c|c|c|}
\hline \multirow{3}{*}{$\begin{array}{l}\text { Variables } \\
\text { Average }\end{array}$} & \multicolumn{2}{|c|}{$\begin{array}{l}\text { Adjusted means (standard } \\
\text { deviation), based on mixed-effect } \\
\text { models }\end{array}$} & \multicolumn{4}{|c|}{$\begin{array}{l}\text { Mean difference Controls/RP vs. AIR/ } \\
\text { AIR-RP in subgroups ( } p \text {-values) }\end{array}$} & \multirow{3}{*}{$\begin{array}{l}P \text {-values } \\
\text { Group effect }\end{array}$} \\
\hline & \multirow[t]{2}{*}{ Controls } & \multirow[t]{2}{*}{$\mathrm{RP}$} & \multicolumn{2}{|c|}{ Controls vs. } & \multicolumn{2}{|l|}{ RP vs. } & \\
\hline & & & AIR & AIR-RP & AIR & AIR-RP & \\
\hline \multicolumn{8}{|c|}{$\mathrm{A}-\mathrm{SO}_{2}(\%)$} \\
\hline Average & $93.91( \pm 4.09)$ & $97.94( \pm 6.41)$ & $\begin{array}{l}-4.17 \\
(0.073)\end{array}$ & $\begin{array}{l}-6.50^{\mathrm{a}} \\
(0.021)\end{array}$ & $\begin{array}{l}-0.14 \\
(0.962)\end{array}$ & $\begin{array}{l}-2.47 \\
(0.375)\end{array}$ & $<0.001^{\mathrm{a}}$ \\
\hline \multicolumn{8}{|c|}{$\mathrm{V}-\mathrm{SO}_{2}(\%)$} \\
\hline Average & $56.23( \pm 6.45)$ & $62.20( \pm 8.20)$ & $\begin{array}{l}-11.55^{\mathrm{a}} \\
(<0.001)\end{array}$ & $\begin{array}{l}-16.01^{\mathrm{a}} \\
(<0.001)\end{array}$ & $\begin{array}{l}-5.58 \\
(0.081)\end{array}$ & $\begin{array}{l}-10.04^{\mathrm{a}} \\
(0.010)\end{array}$ & $<0.001^{\mathrm{a}}$ \\
\hline \multicolumn{8}{|c|}{$A-V \mathrm{SO}_{2}(\%)$} \\
\hline Average & $37.67( \pm 5.75)$ & $35.73( \pm 8.61)$ & $\begin{array}{l}7.39^{\mathrm{a}} \\
(0.024)\end{array}$ & $\begin{array}{l}9.51^{\mathrm{a}} \\
(0.016)\end{array}$ & $\begin{array}{l}5.45 \\
(0.092)\end{array}$ & $\begin{array}{l}7.57 \\
(0.053)\end{array}$ & $0.016^{\mathrm{a}}$ \\
\hline \multicolumn{8}{|l|}{$D-A(\mu m)$} \\
\hline Average & $88.40( \pm 10.64)$ & $83.64( \pm 11.88)$ & $\begin{array}{l}9.31 \\
(0.053)\end{array}$ & $\begin{array}{l}13.00^{\mathrm{a}} \\
(0.025)\end{array}$ & $\begin{array}{l}4.55 \\
(0.337)\end{array}$ & $\begin{array}{l}8.25 \\
(0.151)\end{array}$ & $0.013^{\mathrm{a}}$ \\
\hline \multicolumn{8}{|l|}{$D-V(\mu m)$} \\
\hline Average & $115.94( \pm 13.18)$ & $105.41( \pm 16.50)$ & $\begin{array}{l}21.65^{\mathrm{a}} \\
(0.001)\end{array}$ & $\begin{array}{l}23.83^{\mathrm{a}} \\
(0.003)\end{array}$ & $\begin{array}{l}11.17 \\
(0.084)\end{array}$ & $\begin{array}{l}13.30 \\
(0.087)\end{array}$ & $<0.001^{\mathrm{a}}$ \\
\hline
\end{tabular}

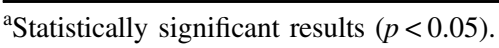

slight increase in the $\mathrm{A}-\mathrm{SO}_{2}$ with a mean $\pm \mathrm{SD}$ to $98.07 \pm$ $1.90 \%(p=0.375)$, a statistically significant increase in the $\mathrm{V}$ $\mathrm{SO}_{2}$ with a mean $\pm \mathrm{SD}$ of $72.24 \pm 9.04 \%(p=0.010)$, and a decrease in the $\mathrm{A}-\mathrm{V} \mathrm{SO}_{2}$ with a mean $\pm \mathrm{SD} 28.16 \pm 10.98 \%$ $(p=0.053)$. Meanwhile, the AIR group differed from the RP group by slightly higher $\mathrm{A}-\mathrm{SO}_{2}$ of $98.07 \pm 1.90 \%(p=0.962)$, higher $\mathrm{V}-\mathrm{SO}_{2}$ of $67.79 \pm 6.87 \%(p=0.081)$ and by a lower A$\mathrm{V} \mathrm{SO}_{2}$ of $30.29 \pm 37.38 \%(p=0.092$; Table 2$)$, which however did not reach statistically significant levels.

Thus, a novel finding in the present study is that both, the AIR and AIR-RP groups, differed from the RP group with AIR and AIR-RP eyes showing slightly higher $\mathrm{A}-\mathrm{SO}_{2}$ and $\mathrm{V}-\mathrm{SO}_{2}$ values and lower $\mathrm{A}-\mathrm{V} \mathrm{SO} \mathrm{S}_{2}$ values, when compared to the RP group.

\section{Comparison between AIR-RP and AIR subgroups}

The subgroup comparison showed that the AIR-RP subgroup tended to have higher $\mathrm{A}-\mathrm{SO}_{2}$ and $\mathrm{V}-\mathrm{SO}_{2}$ values than the AIR group, but slightly lower $\mathrm{A}-\mathrm{V} \mathrm{SO}_{2}$ values (Fig. 2), however not reaching statistically significant values.

\section{Retinal vessel diameter results}

\section{Comparison with healthy control eyes}

Basically, AIR patients (isolated AIR, as well as AIR-RP) showed more attenuated vessel diameters (both, the D-A and the $\mathrm{D}-\mathrm{V})$, when compared to controls.

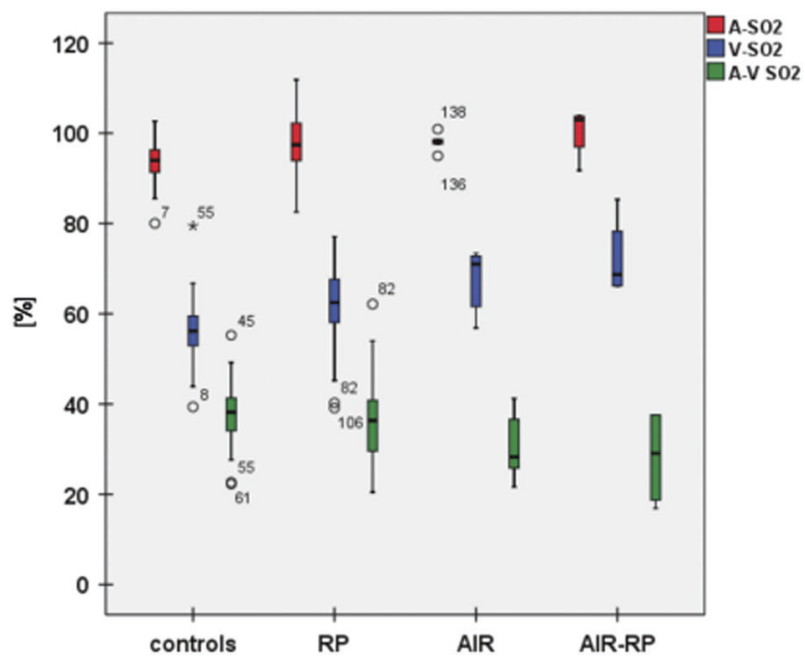

Fig. 2 Box plot analysis illustrates the vessel oxygen saturation of the retinal arterioles (red, $\mathrm{A}-\mathrm{SO}_{2}$ ), venules (blue, $\mathrm{V}-\mathrm{SO}_{2}$ ), and their difference (green, $\mathrm{A}-\mathrm{V} \mathrm{SO}_{2}$ ). The ordinate shows the vessel oxygen saturation in percent for healthy control eyes (left side), eyes with isolated retinitis pigmentosa ( $\mathrm{RP}$, middle left), eyes with isolated autoimmune retinopathy (AIR, middle right), and eyes with combined retinitis pigmentosa and autoimmune retinopathy (AIR-RP, right side) shown on the abscissa

Evaluated in subgroups, patients with AIR and AIR-RP differed from controls by D-A. Both subgroups showed a trend for arteriolar diameter attenuation with the mean values of $79.09 \pm 7.56 \mu \mathrm{m}(p=0.053)$ and $75.40 \pm 3.14 \mu \mathrm{m}$ $(p=0.025)$, respectively, when compared to $88.40 \pm 10.64$ 


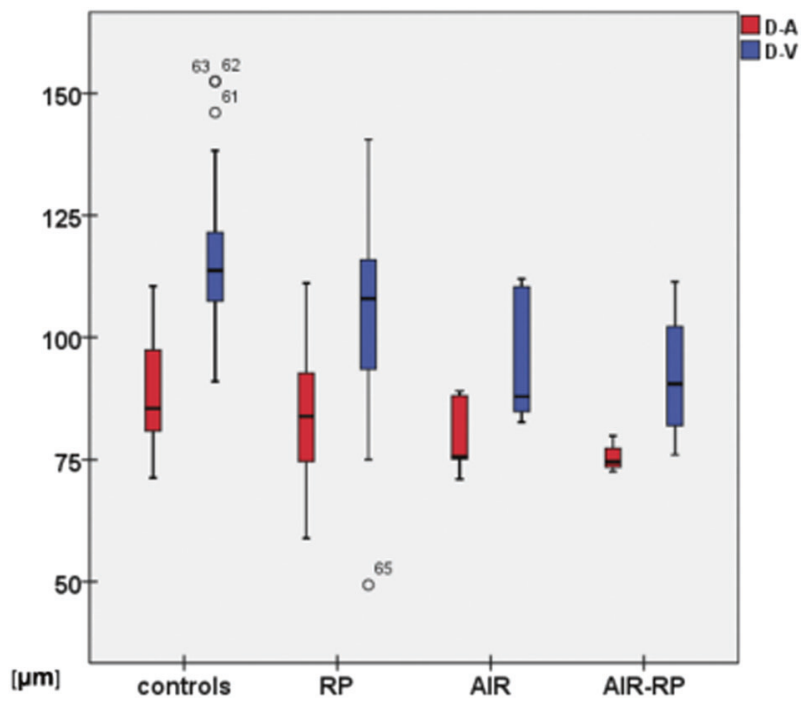

Fig. 3 Box plot analysis illustrates the diameter of the retinal arterioles (red, D-A) and venules (blue, D-V). The ordinate shows the diameter in $\mu \mathrm{m}$ for healthy control eyes (left side), eyes with isolated retinitis pigmentosa (RP, middle left), eyes with isolated autoimmune retinopathy (AIR, middle right), and eyes with combined retinitis pigmentosa and autoimmune retinopathy (AIR-RP, right side) shown on the abscissa

$\mu \mathrm{m}$ in controls. The $\mathrm{D}-\mathrm{V}$ also showed significant attenuation with mean values of $94.29 \pm 13.24 \mu \mathrm{m}(p=0.001)$ and $92.11 \pm 14.69 \mu \mathrm{m}(p=0.003)$, respectively, when compared to $115.94 \pm 13.18 \mu \mathrm{m}$ in controls (Table 2 and Fig. 3).

\section{Comparison with eyes suffering from RP}

Consistent with the results of previous studies [9-15] isolated RP differed from controls: the mean retinal D-A and D-V values decreased (Table 2; Fig. 3).

Subgroup analysis revealed almost equally attenuated retinal vessel diameters (D-A and D-V) in patients with AIR and AIR-RP, when compared to those in patients with isolated RP $(p>0.34)$.

In order to exclude the effect of age on the evaluated data, the age dependency was included in our linear mixed-effect model, as well. In our study, age showed no significant influence neither for oxygen saturation levels $(p>0.90)$, nor for retinal vessel diameter measurements $(p>0.47)$.

\section{Discussion}

AIR encompasses a spectrum of rare autoimmune diseases, which may masquerade a progressive relapsing RP. Careful evaluation for positive history of preexisting cancerosis, melanoma, or lymphoma should be performed in the presence of newly reported central vision-, or visual field deterioration in order to rule out a paraneoplastic retinopathy. The clinical, electrophysiological, and immunological heterogeneity of the disease usually results in a delay of the diagnosis and thus, in irreversible vision loss, even if the treatment is necessitated. The precise triggers that lead to a sudden autoimmune attack on retinal proteins are still under investigation [17-20].

Alterations in metabolic function in patients with progressive outer receptor degeneration have been described before $[10,11,14,15,30,31]$. In patients with AIR, the cross-reaction between antigens expressed by the underlying tumor and retinal proteins, is presumed to initiate photoreceptor cell death with further tissue remodeling-a process that shares similar features with RP. Therefore, in analogy to the studies cited above on oxygen saturation in inherited retinal diseases, it could be assumed that patients suffering from AIR may also suffer from metabolic dysfunction. Nevertheless, the effect of the autoimmune disease on metabolic retinal function has not been studied yet. Furthermore, given the fact that RP is a quite frequent entity with a prevalence of 1:2500 to 1:7000 [32] one would expect a superposition and relapsing photoreceptor loss in the presence of AIR.

Thus, we aimed to investigate on both: weather patients suffering from AIR and AIR-RP could be differentiated not only from controls, but also from patients suffering from isolated RP, and also to what extend the AIR and AIR-RP subgroups differ from each other.

A novel finding in our study is that patients with AIR and those with combined RP and AIR suffer from metabolic dysfunction. Both subgroups could clearly be differentiated from controls by increased $\mathrm{V}-\mathrm{SO}_{2}$ value $(p<$ $0.001)$ and reduced $\mathrm{A}-\mathrm{V} \mathrm{SO}_{2}(p<0.025)$. In analogy, taking results of previous studies on patients suffering from rod-cone dystrophy into account, showed also a significant increase in $\mathrm{V}-\mathrm{SO}_{2}$ and a significant decrease in $\mathrm{A}-\mathrm{V} \mathrm{SO} 2[9-12,14,15]$. These findings are explained in part as a result of the loss of oxygen-consuming photoreceptors [7], increased tissue oxygen tension toward the inner retina [33], and the resulting secondary increase of the extracellular oxygen levels in the inner retina [34-36]. Since AIR - in analogy to rod-cone dystrophy-is associated with rod and cone dysfunction due to the presence of antiretinal anti-photoreceptor cell and anti-ganglion cell antibodies [37, 38] a comparable pathophysiological mechanism in terms of metabolic dysfunction could be assumed.

Basically, autoimmune antiretinal antibodies are discussed to play a pathologic role both in RP and in AIR [28]. As both clinical entities share similar clinical features, and taking RP as a simple model for progressive outer receptor degeneration, it could be assumed that RP and AIR may present also similar metabolic alterations-a hypothesis now confirmed in the present study. 
Moreover, we noted that patients suffering from combined AIP-RP showed severely impaired metabolic function than those suffering from isolated AIR. Hence, patients with AIR-RP showed significantly higher $\mathrm{V}-\mathrm{SO}_{2}$ values, when compared to patients with isolated RP $(p<0.01)$. In daily clinical practice the diagnosis of AIR needs to be taken into consideration in case of recently occurred and progressive visual deterioration, flickering scotomas, visual field defects, especially in the presence of progressive retinal vessel attenuation combined with scotopic negative ERGs and reduced on-off ERGs [17, 23]. However, as exemplified in our patients 4 and 5 , in the presence of underlying $\mathrm{RP}$, the diagnosis of an overlapping AIR could simply be overlooked. Based on our results, AIR-RP eyes seem to present with even worse progression of photoreceptor dysfunction-a finding which explains higher venular vessel saturation, when compared to those with isolated RP. Thus, our results seem to be not that promising in differentiating between RP patients from AIR, but very helpful when a relapse of the RP degenerative process, or an overlapping AIR in the presence of underlying RP, are suspected. Hence, RO seems to be a promising diagnostic tool.

Attenuation of retinal vessels is a typical clinical finding in eyes with AIR [17]. In agreement, we found a significant attenuation of venular vessel diameter (D-V) in eyes with AIR, as well as in eyes with combined AIR-RP, when compared to healthy controls $(p<0.003)$. Even more, eyes with combined AIR-RP presented with significantly narrower retinal arterioles $(p<0.002)$. Several possible mechanisms in regard to vascular attenuation in AIR and in AIR-RP have already been supposed in the literature, as: due to tissue remodelling following photoreceptor cells death; due to secondary small and medium-sized blood vessels vasculitis, as well as due to endothelial inflammation, fibrinoid necrosis, lymphoproliferation and immune-complex-binding as part of paraneoplastic syndrome [39, 40]. Our study could show that tissue remodelling in eyes with AIR and AIR-RP is at least as severe as in eyes suffering from RP.

As already mentioned above, patients suffering from combined AIP-RP showed severely impaired metabolic function, as those suffering from isolated AIR. With this finding for the first time a cumulative effect for eyes suffering from both, RP and AIR, when compared to those with isolated AIR or isolated RP, could be shown. Therefore, RO may support the differentiation between isolated and combined presentations of retinal diseases.

Limitations of our study include the small number of observed eyes suffering from isolated AIR and combined AIR-RP. However, since AIR is a very rare entity, it is very difficult to enroll a large number of patients. Nevertheless, even with a small number of observations (ten eyes suffering from AIR) a significant difference in retinal oxygen saturation could be detected, when compared to both, healthy controls and eyes suffering from RP. In order to confirm the presented results in a larger cohort further prospective, randomized multicenter studies with higher number of cases are needed in the future.

In conclusion, our results indicate that oxygen metabolism is altered in AIR patients. Therefore, RO might be a valuable tool in monitoring disease progression and evaluating potential therapeutic responses in the future.

\section{Summary}

\section{What was known before}

- Patients with RP present with significant changes in the retinal oxygen saturation-a phenomenon that can be used as a diagnostic hallmark in daily clinical practice.

\section{What this study adds}

- Isolated AIR presents with similar findings in retinal oxygen saturation as RP patients.

- Combined presentations of patients suffering from both, AIR and RP, show a cumulative effect with even more severe changes in retinal oxygen saturation.

- Thus, RO might serve as a useful tool to support the diagnosis of AIR, respectively of AIR-RP.

Acknowledgements We thank Dr. Andy Schoetzau for statistical advice.

\section{Compliance with ethical standards}

Conflict of interest The authors declare that they have no conflict of interest.

\section{References}

1. Schweitzer D, Thamm E, Hammer M, Kraft J. A new method for the measurement of oxygen saturation at the human ocular fundus. Int Ophthalmol. 2001;23:347-53.

2. Hammer M, Thamm E, Schweitzer D. A simple algorithm for in vivo ocular fundus oximetry compensating for non-haemoglobin absorption and scattering. Phys Med Biol. 2002;47:233-8.

3. Hardarson SH, Harris A, Karlsson RA, Halldorsson GH, Kagemann L, Rechtman E, et al. Automatic retinal oximetry. Invest Ophthalmol Vis Sci. 2006;47:5011-6.

4. Geirsdottir A, Palsson O, Hardarson SH, Olafsdottir OB, Kristjansdottir JV, Stefánsson E. Retinal vessel oxygen saturation in healthy individuals. Invest Ophthalmol Vis Sci. 2012;13:5433-42.

5. Stefánsson E, Wolbarsht ML, Landers $\mathrm{MB}$ 3rd. In vivo $\mathrm{O}_{2}$ consumption in rhesus monkeys in light and dark. Exp Eye Res. 1983;37:251-6.

6. Wangsa-Wirawan ND, Linsenmeier RA. Retinal oxygen: fundamental and clinical aspects. Arch Ophthalmol. 2003;121:547-57.

7. Yu DY, Cringle SJ. Oxygen distribution and consumption within the retina in vascularised and avascular retinas and in animal models of retinal disease. Prog Retin Eye Res. 2001;20:175-208. 
8. Yu DY, Cringle SJ. Retinal degeneration and local oxygen metabolism. Exp Eye Res. 2005;80:745-51.

9. Türksever C, Valmaggia C, Orguel S, Schorderet DF, Todorova MG. Retinal vessel oxygen saturation in retinitis pigmentosa patients. In: EVER meeting2013 Nizza: E-abstract eTO23 Acta Ophthalmologica 2013;91:s252.

10. Todorova MG, Türksever C, Schorderet DF, Valmaggia C. Retinal vessel oxygen saturation in patients suffering from inherited diseases of the retina. Klin Monbl Augenheilkd. 2014;231:447-52.

11. Türksever C, Valmaggia C, Orgül S, Schorderet DF, Flammer J, Todorova MG. Retinal vessel oxygen saturation and its correlation with structural changes in retinitis pigmentosa. Acta Ophthalmol. 2014;92:454-60.

12. Eysteinsson T, Hardarson SH, Bragason D, Stefánsson E. Retinal vessel oxygen saturation and vessel diameter in retinitis pigmentosa. Acta Ophthalmol. 2014;92:449-53.

13. Ueda-Consolvo T, Fuchizawa C, Otsuka M, Nakagawa T, Hayashi A. Analysis of retinal vessels in eyes with retinitis pigmentosa by retinal oximeter. Acta Ophthalmol. 2015;93:446-50.

14. Todorova MG, Türksever C, Schötzau A, Schorderet DF, Valmaggia C. Metabolic and functional changes in retinitis pigmentosa: comparing retinal vessel oximetry to full-field electroretinography, electrooculogram and multifocal electroretinography. Acta Ophthalmol. 2016;94:231-41.

15. Bojinova RI, Türksever C, Schötzau A, Valmaggia C, Schorderet DF, Todorova MG. Reduced metabolic function and structural alterations in inherited retinal dystrophies: investigating the effect of peripapillary vessel oxygen saturation and vascular diameter on the retinal nerve fibre layer thickness. Acta Ophthalmol. 2016;95:252-61.

16. Sawyer RA, Selhorst JB, Zimmerman LE, Hoyt WF. Blindness caused by photoreceptor degeneration as a remote effect of cancer. Am J Ophthalmol. 1976;81:606-13.

17. Grange L, Dalal M, Nussenblatt RB, Sen HN. Autoimmune retinopathy. Am J Ophthalmol. 2014;157:266-72.

18. Forooghian F, Macdonald IM, Heckenlively JR, Héon E, Gordon LK, Hooks JJ, et al. The need for standardization of antiretinal antibody detection and measurement. Am J Ophthalmol. 2008;146:489-95.

19. Kondo M, Sanuki R, Ueno S, Nishizawa Y, Hashimoto N, Ohguro $\mathrm{H}$, et al. Identification of autoantibodies against TRPM1 in patients with paraneoplastic retinopathy associated with ON bipolar cell dysfunction. PLoS ONE. 2011;6:e19911.

20. Sen HN, Nussenblatt RB. Autoimmune retinopathies. In: Ryan, SJ, Schachat, AP, Wilkinson, CP, et al., editors. Retina 2013. 5th ed. United Kingdom: Elsevier; 2013: p. 1381-9.

21. Chan JW. Paraneoplastic retinopathies and optic neuropathies. Surv Ophthalmol. 2003;48:12-38.

22. Adamus G, Ren G, Weleber RG. Autoantibodies against retinal proteins in paraneoplastic and autoimmune retinopathy. BMC Ophthalmol. 2004;4:5-13.
23. Todorova MG, Palmowski-Wolfe AM, Leifert D, Prünte C, Meyer P. Unilateral nocturnal glare sensitivity and photopsias. Ophthalmologe. 2006;103:533-6.

24. Ferreyra HA, Jayasundera $\mathrm{T}$, Khan NW, He S, Lu Y, Heckenlively JR. Management of autoimmune retinopathies with immunosuppression. Arch Ophthalmol. 2009;127:390-7.

25. Sahel J, Bonnel S, Mrejen S, Paques M. Retinitis pigmentosa and other dystrophies. Dev Ophthalmol. 2010;47:160-7.

26. Fox AR, Gordon LK, Heckenlively JR, Davis JL, Goldstein DA, Lowder CY, et al. Consensus on the diagnosis and management of nonparaneoplastic autoimmune retinopathy using a modified delphi approach. Am J Ophthalmol. 2016;168:183-90.

27. Todorova MG, Bojinova RI, Valmaggia C, Schorderet DF. Prominent optic disc featured in inherited retinopathy. Klin Monbl Augenheilkd. 2017;234:577-83.

28. Heckenlively JR, Ferreyra HA. Autoimmune retinopathy: a review and summary. Semin Immunopathol. 2008;30:127-34.

29. Heckenlively JR, Solish AM, Chant SM, Meyers-Elliott RH. Autoimmunity in hereditary retinal degenerations. II. Clinical studies: antiretinal antibodies and fluorescein angiogram findings. Br J Ophthalmol. 1985;69:758-64.

30. Lopez Torres LT, Türksever C, Schötzau A, Orgül S, Todorova MG. Peripapillary retinal vessel diameter correlates with mfERG alterations in retinitis pigmentosa. Acta Ophthalmol. 2015;93:527-33.

31. Konieczka K, Bojinova RI, Valmaggia C, Schorderet DF, Todorova MG. Preserved functional and structural integrity of the papillomacular area correlates with better visual acuity in retinitis pigmentosa. Eye. 2016;30:1310-23.

32. Permeggiani F. Clinics, edidemiology and genetics of retinitis pigmentosa. Curr Genom. 2011;12:236-7.

33. Shahidi M, Wanek J, Blair NP, Little DM, Wu T. Retinal tissue oxygen tension imaging in the rat. Invest Ophthalmol Vis Sci. 2010;51:4766-70.

34. Marc RE, Jones BW. Retinal remodeling in inherited photoreceptor degenerations. Mol Neurobiol. 2003;28:139-47.

35. Marc RE, Jones BW, Watt CB, Strettoi E. Neural remodeling in retinal degeneration. Prog Retin Eye Res. 2003;22:607-55.

36. Cottet S, Schorderet DF. Mechanisms of apoptosis in retinitis pigmentosa. Curr Mol Med. 2009;9:375-83.

37. Hooks JJ, Tso MOM, Detrick B. Retinopathies associated with antiretinal antibodies. Clin Diagn Lab Immunol. 2001;8:853-8.

38. Keltner JL, Roth AM, Chang RS. Photoreceptor degeneration. Possible autoimmune disorder. Arch Ophthalmol. 1983;101:564-9.

39. Pirayesh A, Verbunt RJ, Kluin PM, Meinders AE, De Meijer PH. Myelodysplastic syndrome with vasculitic manifestations. J Intern Med. 1997;242:425-31.

40. Ju W, Park IA, Kim SH, Lee SE, Kim SC. Small cell carcinoma of the uterine corpus manifesting with visual dysfunction. Gynecol Oncol. 2005;99:504-6. 